\title{
A brief review of liver injury in patients with Corona Virus Disease-19 during the pandemic
}

\author{
Maham Farshidpour $^{1} \cdot$ David Kim $^{2} \cdot$ Shilpa Junna ${ }^{2} \cdot$ Juanita Merchant $^{2}$ \\ Received: 28 May 2020 / Accepted: 18 June 2020 / Published online: 3 July 2020 \\ (C) Indian Society of Gastroenterology 2020
}

\begin{abstract}
The novel coronavirus Severe Acute Respiratory Syndrome Corona Virus-2 (SARS-CoV-2) infection has been mostly leading to respiratory distress syndrome, but liver injury has also been documented. The mechanism of liver injury is limited and poorly understood. However, the hepatic injury could be due to a consequence of systemic inflammatory response, viral infection of hepatocytes, or as a result of intensive care treatment or drug toxicity. Based on the current studies, this review article emphasizes on the demographic and potential mechanisms of Corona Virus Disease (COVID)-19-related liver dysfunction
\end{abstract}

Keywords COVID-19 $\cdot$ Liver injury $\cdot$ Liver transplant

\section{Introduction}

Corona Virus Disease (COVID)-19 is a respiratory viral infection caused by a newly emergent coronavirus, Severe Acute Respiratory Syndrome Corona Virus-2 (SARS-CoV-2), which started in Wuhan, China, in December 2019 and has since evolved into a pandemic with a global risk to human health [1]. While the majority of infected patients with COVID-19 have mild or uncomplicated disease, nearly $14 \%$ of patients may develop severe symptoms requiring hospitalization and oxygen support, and 5\% require aggressive treatment with admission to an intensive care unit (ICU) [2]. This virus can lead to respiratory, intestinal, and hepatic injury, and may cause acute respiratory distress syndrome (ARDS), septic shock with multi-organ failure, and even death in severe cases [3, 4]. Fever, dry cough, and shortness of breath are the main clinical manifestations of SARSCoV-2 infection [5]. Although abnormal liver enzymes were regularly described as an extrapulmonary clinical feature, and almost one half of patients experienced grades of hepatic injury [6-9], liver damage in patients with SARS infections was primarily manifested in the mild and moderate elevation of alanine

Maham Farshidpour

Mfarshidpour@email.arizona.edu

1 Division of Inpatient Medicine, Banner University Medical Center, Tucson, AZ, USA

2 Division of Gastroenterology and Hepatology, Banner University Medical Center, Tucson, AZ, USA and/or aspartate aminotransferases (ALT and AST) with some degree of hypoalbuminemia and hyperbilirubinemia during the early stage of the illness $[10,11]$. The average level of ALT from $56.07 \mathrm{U} / \mathrm{L}$ to $111.32 \mathrm{U} / \mathrm{L}$ and the average serum albumin from $37.25 \mathrm{~g} / \mathrm{L}$ to $34.26 \mathrm{~g} / \mathrm{L}$ at the day of admission throughout the third week after hospitalization, respectively were reported in patients with acute respiratory syndrome [12]. In this brief review article, we summarized the characteristics and mechanism of liver injury in patients with SARS-CoV-2 infection, with the hope of guiding further study on this important topic.

\section{Methods}

Medline/Pubmed databases were searched thoroughly with search strategies using search keywords "COVID-19", "liver injury", "ICU admission", and "epidemiology", to classify studies published between the years 2019 and 2020. All types of related studies were selected. Adults with COVID-19 infection and liver injury were included. Studies related to nonhumans were excluded from our review. All selected articles were reviewed by the authors for relevance to COVID-19 and liver injury.

\section{Epidemiology of liver injury in COVID-19}

COVID-19 is a novel infection caused by SARS-CoV-2 and the number of cases is still rapidly growing worldwide [13, 
14]. Current data on COVID-19 have reported that the incidence of abnormal ALT/AST levels varies from $14.8 \%$ to $53 \%[15,16]$. Patients with more severe COVID-19 appear to have higher rates of hepatitis with elevation of liver enzyme compared with mild to moderate disease (Table 1).

In a prospective study, Huang et al. reported elevation of AST in eight $(62 \%)$ of 13 patients in the ICU compared with seven $(25 \%)$ of 28 patients who did not require medical treatment in the ICU [16]. Additionally, Guan et al. showed that $39.4 \%$ of patients with severe COVID-19 requiring ICU admission and mechanical ventilation had AST $>40 \mathrm{U} / \mathrm{L}$ compared with $18.2 \%$ of non-severe cases [17]. In the multicenter retrospective study, the mean level of AST and ALT in 32 patients was significantly higher compared with controls [18]. The majority of patients had elevated AST/ALT; however, Chan et al. documented a cholestatic pattern of liver injury, with elevation in alkaline phosphatase to $211 \mathrm{U} / \mathrm{L}$ in one out of seven patients infected with the virus [19]. In a retrospective study, Xie et al. described that in 79 COVID-19 non-ICU patients, transaminase elevation was more common in male patients who also had leukocytosis, elevated C-reative protein (CRP), and more lesions in lung by computerized tomography (CT) scan with a longer length of stay in hospital $(p<$ 0.05 ) [20]. In concordance with the previous study, patients with hepatic injury had higher inflammatory markers, such as elevated CRP and reduced absolute numbers of lymphocytes such as T cells, and in severe cases of COVID-19, hepatic injury was complicated by greater activation of coagulation and fibrinolytic pathways [7, 21, 22].

Table 1 Liver test abnormalities from various Corona Virus Disease (COVID)-19 studies

\begin{tabular}{|c|c|c|c|c|c|c|c|c|}
\hline Article & Patient category & AST U/L & ALT U/L & ALP U/L & $\begin{array}{l}\text { Total bilirubin } \\
\mu \mathrm{mol} / \mathrm{L}\end{array}$ & $\begin{array}{l}\text { Albumin } \\
\mathrm{g} / \mathrm{L}\end{array}$ & $\begin{array}{l}\mathrm{PT} \\
\mathrm{S}\end{array}$ & $\begin{array}{l}\text { APTT } \\
\text { S }\end{array}$ \\
\hline \multirow[t]{3}{*}{ Yang et al. [8] } & Total patient & - & - & - & - & - & - & - \\
\hline & Severe/nonsurvivor & - & - & - & 19.1 & - & 12.9 & - \\
\hline & Non-severe/survivor & - & - & - & 13.1 & - & 10.9 & - \\
\hline \multirow[t]{3}{*}{ Arentz et al. [9] } & All patient & $\begin{array}{l}34 \\
(5-40)\end{array}$ & $\begin{array}{l}26.5 \\
(5-50)\end{array}$ & $\begin{array}{l}80 \\
(31-120)\end{array}$ & $\begin{array}{l}0.6^{\mathrm{a}} \\
(0-1.5)\end{array}$ & - & - & - \\
\hline & Severe/nonsurvivor & - & - & - & - & - & - & - \\
\hline & Non-severe/survivor & - & - & - & - & - & - & - \\
\hline \multirow[t]{3}{*}{ Chen et al. [6] } & Total patient & $\begin{array}{l}34 \\
(15-40)\end{array}$ & $\begin{array}{l}39 \\
(9-50)\end{array}$ & - & $\begin{array}{l}15.1 \\
(0-21)\end{array}$ & $\begin{array}{l}31.6 \\
(40-55)\end{array}$ & $\begin{array}{l}11.3 \\
(10.5-13.5)\end{array}$ & $\begin{array}{l}27.3 \\
(21-37)\end{array}$ \\
\hline & Non-severe/survivor & - & - & - & - & - & - & - \\
\hline & Severe/nonsurvivor & - & - & - & - & - & - & - \\
\hline \multirow[t]{3}{*}{ Wu et al. [11] } & Total patient & $\begin{array}{l}30 \\
(15-40)\end{array}$ & $\begin{array}{l}24 \\
(9-50)\end{array}$ & - & $\begin{array}{l}6.6 \\
(0-21)\end{array}$ & $\begin{array}{l}38 \\
(40-55)\end{array}$ & $\begin{array}{l}10.6 \\
(10.5-13.5)\end{array}$ & $\begin{array}{l}18.6 \\
(21-37)\end{array}$ \\
\hline & Severe/nonsurvivor & - & - & - & - & - & - & - \\
\hline & Non-severe/survivor & - & - & - & - & - & - & - \\
\hline \multirow[t]{3}{*}{ Qian et al. [14] } & Total patient & $\begin{array}{l}21 \\
(15-40)\end{array}$ & $\begin{array}{l}18 \\
(9-50)\end{array}$ & - & - & $\begin{array}{l}40 \\
(40-55)\end{array}$ & - & - \\
\hline & Severe/nonsurvivor & 27 & 19.9 & - & - & 38.8 & - & - \\
\hline & Non-severe/survivor & 21 & 18 & - & - & 4.2 & - & - \\
\hline \multirow[t]{3}{*}{ Wang et al. [7] } & Total patient & $\begin{array}{l}31 \\
(15-40)\end{array}$ & $\begin{array}{l}24 \\
(9-50)\end{array}$ & - & $\begin{array}{l}9.8 \\
(5-21)\end{array}$ & - & $\begin{array}{l}13 \\
(9.4-12.5)\end{array}$ & $\begin{array}{l}31.4 \\
(25.1-36.5)\end{array}$ \\
\hline & Severe/nonsurvivor & 52 & 35 & - & 11 & - & 13.2 & 30.4 \\
\hline & Non-severe/survivor & 29 & 23 & - & 9.3 & - & 12.9 & 31.7 \\
\hline \multirow[t]{3}{*}{ Lo et al. [15] } & Total patient & $\begin{array}{l}20 \\
(<41)\end{array}$ & $\begin{array}{l}24 \\
(<40)\end{array}$ & - & $\begin{array}{l}6 \\
(0-24)\end{array}$ & - & $\begin{array}{l}12.2 \\
(12.2)\end{array}$ & $\begin{array}{l}34.5 \\
(30)\end{array}$ \\
\hline & Severe/nonsurvivor & 24 & - & - & - & - & - & - \\
\hline & Non-severe/survivor & 19 & - & - & - & - & - & - \\
\hline \multirow[t]{3}{*}{ Huang et al. [16] } & Total patient & - & 32 & - & 11.7 & 31.4 & 11.1 & 27 \\
\hline & Severe/nonsurvivor & - & 49 & - & 14 & 27.9 & 12.2 & 26.2 \\
\hline & Non-severe/survivor & - & 27 & - & 10.8 & 34.7 & 10.7 & 27.7 \\
\hline
\end{tabular}

Data is mean (SD) or median (interquartile range [IQR]) depending on the original study with normal range in the parentheses. ${ }^{a} \mathrm{mg} / \mathrm{dL} . A S T$ aspartate aminotransferase, $A L T$ alanine aminotransferase, $A L P$ alkaline phosphatase, $U / L$ units per litre, PTS prothrombin time in seconds, APTTS activated partial thromboplastin time in second 


\section{Liver injury and severity of COVID-19}

A study in China showed that COVID-19 patients with abnormal liver enzyme of hepatocellular or mixed types (elevated ALT/ AST, or both ALT/AST and ALP/gamma-glutamyl transpeptidase [GGT]) had higher odds of progression to severe COVID-19 compared with patients with normal liver tests (odds ratios 2.73 ; 95\% confidnec interval [CI] 1.19-6.3, and 4.44, 95\% CI 1.93-10.23, respectively) [23]. Additionally, in a systematic review and meta-analysis of 20 retrospective studies with 3428 COVID-19 patients (severe cases $=1455$ and mild cases = 1973), higher serum levels of AST (weighted mean difference $=8.84 \mathrm{U} / \mathrm{L}, 95 \% \mathrm{CI}=5.97$ to $11.71, p<0.001$ ), ALT (weighted mean difference $=7.35 \mathrm{U} / \mathrm{L}, 95 \% \mathrm{CI}=4.77$ to $9.93, p<0.001$ ), total bilirubin (weighted mean difference $=2.30 \mathrm{mmol} / \mathrm{L}, 95 \%$ $\mathrm{CI}=1.24$ to $3.36, p<0.001$ ), and lower serum levels of albumin (weighted mean difference $=-4.24 \mathrm{~g} / \mathrm{L}, 95 \% \mathrm{CI}=-6.20$ to $2.28, p<0.001)$ were associated with a significant increase in the severity of COVID-19 [24].

\section{COVID-19 in liver transplant patients}

Studies regarding COVID-19 in liver transplant patients are limited. Maggi et al. showed that in 17 patients after liver transplant in Italy, two tested positive and one of whom died due to COVID-19 on postoperative day 30 . However, 16 patients survived [25]. Moreover, a similar study in Italy reported three of their 111 long-term liver transplant survivors died after infection with severe COVID-19. All three patients were male, older than 65 years, overweight (body mass index [BMI] $>28$ $\mathrm{kg} / \mathrm{m}^{2}$ ), receiving antihypertensive medication, and had diabetes (median $\mathrm{HbA}_{1 \mathrm{c}}$ of $6.9 \%$ ). They suggested liver transplant patients with metabolic comorbidities should be monitored closely, and also in concordance with the American Association for the Study of Liver Diseases, immunosuppression therapy should not be reduced or discontinued in asymptomatic recipients of liver transplant $[26,27]$.

\section{Mechanism of action}

It is undecided whether the hepatotoxicity of patients with COVID-19 is caused directly by viral infection of hepatocytes or by drug toxicity such as lopinavir/ritonavir, remdesivir, and chloroquine. Earlier ribonucleic acid (RNA) sequence data in the human protein atlas database has demonstrated low expression of the COVID receptor angiotensin converting enzyme 2 (ACE2) in liver, in addition to lung, which is the main target organ for COVID-19 and SARS [28]. Chai et al. identified cholangiocyte specific expression of ACE2 through single-cell RNA sequencing in healthy human livers. They reported that the liver injury of SARS and COVID-19 patients may not be a result of hepatocyte damage, but cholangiocyte dysfunction and other causes such as drug-induced liver injury or a consequence of systemic inflammatory response [29]. Gamma-glutamyl transferase, a diagnostic biomarker for cholangiocyte injury, has not been reported in the existing COVID-19 case studies; however, in an unpublished study by Zhang et al., found that GGT was elevated in $30(54 \%)$ of 56 patients with COVID-19 during hospitalization [1]. $\mathrm{Xu}$ et al. found moderate microvesicular steatosis and mild lobular and portal activity in liver biopsy of a COVID-19 patient. They proposed the injury could have been caused by either SARS-CoV-2 infection or drug-induced liver injury [30]. Additionally, Liu et al. showed presence of hepatomegaly with dark red, hepatocyte degeneration with lobular necrosis and neutrophil infiltration, infiltration of monocytes and lymphocytes in the portal area, and congestion of hepatic sinuses with microthrombosis with no sign of bile duct injury or histological feature of hepatic failure in liver autopsy of critical COVID-19 [31]. Li et al. demonstrated that in 148 patients with COVID-19, 50.7\% had abnormal liver functions at admission, and they reported that the abnormal liver enzyme was significantly higher in cases who received lopinavir/ritonavir compared with patients with normal liver function test. Furthermore, a large number of infected patients had a history of taking antipyretic medication containing paracetamol, which can cause a transient hepatitis [32]. Additional possibilities for the mild hepatitis may be due to hepatic congestion secondary to high levels of positive end-expiratory pressure which can contribute to increased right atrial pressures [33]. Moreover, immune-mediated inflammation, for example cytokines and hypoxia related to pneumonia, might also contribute to liver injury in these patients [1].

\section{Conclusion}

Liver enzymes are often elevated in COVID-19 patients, signifying liver damage. Recent data point to the fact that hepatotoxicity is more frequently occurring in severe COVID-19 cases compared with patients with mild disease. The underlying mechanism of hepatotoxicity in patients with COVID-19 could be due to systemic inflammation, drug-induced liver injury, or pre-existing chronic liver diseases. Current drugs prescribed to treat COVID-19 including oseltamivir, lopinavir/ritonavir, ribavirin, and chloroquine phosphate or hydroxychloroquine sulfate are metabolized in the liver. As a result, frequent and careful monitoring of liver function in patients with COVID-19 can lead to early diagnosis of hepatitis, liver injury, and liver failure. Further study should focus on the mechanisms of liver disease in COVID-19 and the impact of underlying chronic liver disease on treatment and outcome of COVID-19 in the future. 


\section{Compliance with ethical standards}

Conflict of interest MF, DK, SJ, and JM declare that they have no conflict of interest.

Disclaimer The authors are solely responsible for the data and the contents of the paper. In no way, the Honorary Editor-in-Chief, Editorial Board Members, or the printer/publishers are responsible for the results/ findings and content of this article.

\section{References}

1. Zhang C, Shi L, Wang FS. Liver injury in COVID-19: management and challenges. Lancet Gastroenterol Hepatol. 2020;5:428-30.

2. Balla M, Merugu GP, Patel M, et al. COVID-19, Modern pandemic: a systematic review from front-line health care providers' perspective. J Clin Med Res. 2020;12:215-29.

3. Zhu N, Zhang D, Wang W, et al. A novel coronavirus from patients with pneumonia in China, 2019. N Engl J Med. 2020;382:727-33.

4. Xu L, Liu J, Lu M, Yang D, Zheng X. Liver injury during highly pathogenic human coronavirus infections. Liver Int. 2020;40:998-1004.

5. Cascella M, Rajnik M, Cuomo A, Dulebohn SC, Napoli RD. Features, evaluation and treatment coronavirus (COVID-19). Treasure Island (FL): StatPearls Publishing; 2020.

6. Chen N, Zhou M, Dong X, et al. Epidemiological and clinical characteristics of 99 cases of 2019 novel coronavirus pneumonia in Wuhan, China: a descriptive study. Lancet. 2020;395:507-13.

7. Wang D, Hu B, Hu C, et al. Clinical characteristics of 138 hospitalized patients with 2019 novel coronavirus-infected pneumonia in Wuhan, China. JAMA. 2020;323:1061-9. https://doi.org/10.1001/jama.2020. 1585.

8. Yang X, Yu Y, Xu J, et al. Clinical course and outcomes of critically ill patients with SARS-CoV-2 pneumonia in Wuhan, China: a singlecentered, retrospective, observational study. Lancet Respir Med. 2020;8:475-81.

9. Arentz M, Yim E, Klaff L, et al. Characteristics and outcomes of 21 critically ill patients with COVID-19 in Washington State. JAMA. 2020;323:1612-4.

10. Chau TN, Lee KC, Yao H, et al. SARS-associated viral hepatitis caused by a novel coronavirus: report of three cases. Hepatology. 2004;39:302-10.

11. Wu J, Liu J, Zhao X, et al. Clinical characteristics of imported cases of COVID-19 in Jiangsu Province: A multicenter descriptive study. Clin Infect Dis. 2020; ciaa199.

12. Yang Z, Xu M, Yi JQ, Jia WD. Clinical characteristics and mechanism of liver damage in patients with severe acute respiratory syndrome. Hepatobiliary Pancreat Dis Int. 2005;4:60-3.

13. WHO. Coronavirus disease. 2019. http://www.who.int/ emergencies/diseases/novel-coronavirus-2019. Accessed Mar 6.

14. Qian GQ, Yang NB, Ding F, et al. Epidemiologic and clinical characteristics of 91 hospitalized patients with COVID-19 in Zhejiang, China: a retrospective, multi-centre case series. QJM. 2020 Mar 17;hcaa089.

15. Lo IL, Lio CF, Cheong HH, et al. Evaluation of SARS-CoV-2 RNA shedding in clinical specimens and clinical characteristics of 10 patients with COVID-19 in Macau. Int J Biol Sci. 2020;16:1698707.
16. Huang C, Wang Y, Li X, et al. Clinical features of patients infected with 2019 novel coronavirus in Wuhan. China. Lancet. 2020;395: 497-506.

17. Guan WJ, Ni ZY, Hu Y, et al. Clinical characteristics of coronavirus disease 2019 in China. N Engl J Med. 2020;382:1708-20.

18. Liu C, Jiang ZC, Shao CX, et al. Preliminary study of the relationship between novel coronavirus pneumonia and liver function damage: A multicenter study. Zhonghua Gan Zang Bing Za Zhi. 2020;28:107-11.

19. Chan JF, Yuan S, Kok KH, et al. A familial cluster of pneumonia associated with the 2019 novel coronavirus indicating person-toperson transmission: a study of a family cluster. Lancet. 2020;395: 514-23.

20. Xie H, Zhao J, Lian N, Lin S, Xie Q, Zhuo H. Clinical characteristics of non-ICU hospitalized patients with coronavirus disease 2019 and liver injury: a retrospective study. Liver Int. 2020;40:1321-6.

21. Diao B, Wang C, Tan Y, et al. Reduction and functional exhaustion of T cells in patients with coronavirus disease 2019 (COVID-19). Front Immunol. 2020;11:827.

22. Fan Z, Chen L, Li J, et al. Clinical features of COVID-19-related liver functional abnormality. Clin Gastroenterol Hepatol. 2020;18: 1561-6.

23. Cai Q, Huang D, Yu H, et al. COVID-19: Abnormal liver function tests. J Hepatol. 2020:S0168-8278(20)30218-X.

24. Parohan M, Yaghoubi S, Seraj A. Liver injury is associated with severe Coronavirus disease 2019 (COVID-19) infection: a systematic review and meta-analysis of retrospective studies. Hepatol Res. 2020;10.1111/hepr.13510.

25. Maggi U, De Carlis L, Yiu D, et al. The impact of the COVID-19 outbreak on Liver Transplantation programmes in Northern Italy. Am J Transplant. $2020 ; 20: 1840-8$.

26. Bhoori S, Rossi RE, Citterio D, Mazzaferro V. COVID-19 in longterm liver transplant patients: preliminary experience from an Italian transplant centre in Lombardy. Lancet Gastroenterol Hepatol. 2020;5:532-3.

27. American Association for the Study of Liver Diseases Clinical insights for hepatology and liver transplant providers during the COVID-19 pandemic. 2020. https://www.aasld.org/sites/default/ files/2020-03/AASLD-COVID19-ClinicalInsights-3.23.2020FINAL-v2.pdf (accessed Apr 3, 2020).

28. Uhlen M, Fagerberg L, Hallstrom BM, et al. Proteomics. Tissuebased map of the human proteome. Science. 2015;347:1260419.

29. Chai X, Hu L, Zhang Y, et al. Specific ACE2 expression in cholangiocytes may cause liver damage after 2019-nCoV infection. bioRxiv preprint first posted online Feb. 4, 2020. https://doi.org/10. 1101/2020.02.03.931766.

30. Xu Z, Shi L, Wang Y, et al. Pathological findings of COVID-19 associated with acute respiratory distress syndrome. Lancet Respir Med. 2020;8:420-2.

31. Liu QWR, Qu G, Wang Y, et al. General anatomy report of novel coronavirus pneumonia patients. J Forensic Med. 2020;36:19-21.

32. Li J, Fan JG. Characteristics and mechanism of liver injury in 2019 coronavirus disease. J Clin Transl Hepatol. 2020;8:13-7.

33. Bangash MN, Patel J, Parekh D. COVID-19 and the liver: little cause for concern. Lancet Gastroenterol Hepatol. 2020;5:529-30.

Publisher's note Springer Nature remains neutral with regard to jurisdictional claims in published maps and institutional affiliations. 